\title{
IX.
}

\section{Ueber die künstliche Blutleere bei der Transplantation von Hautstückchen.}

\author{
Von \\ Dr. ㅍ. Fischer, \\ Docent der Chirurgie in Strassburg.
}

Im Verlaufe des Wintersemesters von 1879/80 führte ich als Assistent an der hiesigen chirurgischen Klinik eine grössere Zabl von Transplantationen auf granulirende Wundflächen in der Art aus, dass ich die zu verwendenden Hautstückchen vorher künstlich blutleer machte. Dabei stellte sich heraus, dass die Chancen fitr den Erfolg der Transplantation grösser sind, als wenn man in der sonst üblichen Weise verfährt. Nicht nur heilte eine bei Weitem grössere Zahl der Stückchen überhaupt an, sondern es kam auch viel weniger auf die Grösse derselben an, und nicht selten kamen Hautstücke von der Grösse der beim Mikroskopiren gebräuchlichen Objectträger zur Anbeilung.

Abgesehen von dem theoretischen Interesse dieses Verhaltens schien es mir der Mühe werth zu untersuchen, wie sich die Sache gestalten würde, wenn die zu heilende Wunde (Ulcus cruris) ebenfalls vorher künstlich blutleer gemacht wïrde und während der Ausführung der Transplantation durch den oberhalb um das Glied gelegten Esmarch'schen Gummischlauch blutleer gehalten würde. Hierbei ergaben sich noch bessere Resultate, als bei obigem Verfahren. In mehreren Fällen von Beingeschwür wurden letztere mit blutleer gemachten Hautstücken von beliebiger Grösse einfach vollständig zugedeckt, und es trat eine so prompte Anheilung sämmtlicher Stücke ein, dass es unter dem Verbande so zu sagen gar keine Secretion gab; die Lösung und Fäulniss der verhornten Epidermis, ein so bäufiges Vorkommniss bei der Transplantation, blieb aus, die Wunden waren und blieben trocken, es war eine eigentliche greffe dermo-épidermique eingetreten. In anderen Fällen gingen 
allerdings ganze Hautstücke oder Theile derselben ab, jedoch trat letzteres seltener ein, nachdem ich durch Einschneiden einiger kleiner Löcher in dieselben eine Art Drainage anbrachte, welche etwaige Secretansammlungen unter den Hautstilckchen verhüten sollte.

Was das weitere Verhalten der angeheilten transplantirten Stücke anlangt, so liess sich hierin kein besonderer Unterschied gegenüber den in der bisher üblichen Weise ausgeführten Transplantationen feststellen. Einigemale stiessen sich nach mehreren Wochen wieder Hautstiucke ganz oder theilweise los, nachdem die Patienten das Spital verlassen hatten, besonders wenn die Beingeschwüre mechanischen Insulten von Seiten der Schuhe oder grosser Kälte preisgegeben wurden, oder auch wenn sich Schwellung der Beine beim Herumlaufen der Patienten in höherem Grade einstellte.

Betreffend die speciellere Ausfibhrung der Transplantationen, so wurde mir das in der Klinik amputirte und dort bereits mit der elastischen Binde eingewickelte Glied, in der Regel der Unterschenkel, in einigen Fällen gebracht, nacbdem die elastiscbe Binde bereits eine Viertelstunde und länger gelegen batte. Der Erfolg der Transplantation wurde dadurch nicht beeinträchtigt. In anderen Fällen stellte ich selbst an dem abgesetzten Gliede die Blutleere unmittelbar vor der Transplantirung her. Die Stelle, von welcher die Hautstucke entlehnt werden sollten, wurde mit Seife und einer kleinen Bürste gründlich gereinigt, die Haare-abrasirt, mit fünfprocent. Carbol desinficirt, hierauf gründlich abgetrocknet. Sodann wurden die Hautstïcke mit einem scharfen Messer derart ausgeschnitten, dass die Schnittfläche innerhalb der Cutis, aber nirgendwo im subcutanen Gewebe lag, die Haut wurde dabei möglichst gespannt, um eine glatte Schnittfäche zu erhalten. Es ist schwer, gleichmässig. geschnittene Lappen von über $21 / 2-3 \mathrm{Cm}$. Breite zu erhalten, während die Länge derselben je nach der.Länge des amputirten Gliedes ins Belieben gesetzt ist. Die Ränder der so erhaltenen Hautstücke werden wegen des Nachgebens der Haut bei den einzelnen Messerzügen mehr oder weniger zackig, und man hat bei dem Ueberpflanzen auf die granulirende Fläche darauf zu achten, dass diese Zacken sich nicht umlegen.

Die künstliche Blutleere an dem granulirenden Geschwür der Extremitäten wird so hergestellt, dass man das ganze Glied von der Peripherie her mit der $\mathbb{E} s m a r c h ' s c h e n$ Binde einwickelt und bis hoch über das Geschwür hinaufgeht, dann lege man den Gummischlauch um und nehme die Binde ab. Bei der Anlegung der Bindentouren auf dem vorher mit Taffet bedeckten Geschwir muss dar- 
Ueber künstliche Blutleere bei der Transplantation von Hautstückchen. 195

auf geachtet werden, dass die Binde nicht hin und her gleitet und dadureh zu Zerreissung von Granulationen in dem Geschwïr und zu Blutungen unter die transplantirten Stücke nach Lösung des Schlauchs Veranlassung gibt. Ueberhaupt muss bei der Reinigung des Geschwürs vor der Transplantirung in der schonendsten Weise verfahren werden, um Blutungen zu vermeiden. Nach Ausführung der Transplantation wird uber die ganze Wunde Protective gelegt, letzteres mit Heftpflasterstreifen fixirt, daruber Muslin, Guttaperchapapier und eine Gazebinde gelegt. Bei Beingeschwüren kommt dann noch die Drahtkapsel mit Erfolg zur Anwendung. Die Verbände bleiben stets mehrere Tage liegen.

Auf das Alter der Individuen, sowohl derjenigen, von welchen die Haut entlehnt wurde, als derjenigen, denen sie aufgepflanzt wurde, nahm ich keine Rücksicht, es waren Leute von 60 Jahren und mehr unter denselben. Bevor die Patienten das Bett verlassen, ist es, falls die 'Transplantationen die unteren Extremitäten betreffen, zweckmässig, eine porös-elastische Binde umzulegen, damit keine Schwellung der Beine eintritt.

Strassburg, den 24. April 1880. 